\title{
A memorial tribute to Ken Brown
}

\author{
Gary V. Heller, MD, PhD ${ }^{\mathrm{a}, \mathrm{b}}$
}

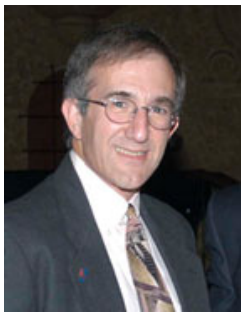

Kenneth A. Brown passed away September 11, 2010 at the age of 58, having lost a courageous battle against cancer. He had been diagnosed with bone cancer several years previous and battled valiantly against this disease. Dr. Brown was the 6th President of the American Society of Nuclear Cardiology. He was an educator, researcher, and innovator in the early days of Nuclear Cardiology.

Dr. Brown's academic career began at Rutgers University, New Brunswick, NJ with a BS degree in Biology and received his MD degree from Cornell Medical School, New York, NY. After his Internal Medicine Internship and Residency at the Peter Bent Brigham Hospital (now Brigham \& Women's Hospital) in Boston, Mass. Ken became a Clinical Research Fellow in Nuclear Cardiology at The Massachusetts General Hospital in the same city where he met and collaborated with Jeffrey Leppo, MD. This was followed by a Cardiovascular Fellowship at the Beth Israel Hospital also in Boston, Massachusetts. It was there that I met and became friends with Ken. We collaborated on several projects during our fellowship which resulted in unique and important contributions to the literature early in his career.

Dr. Brown joined the faculty at the University of Vermont, Fletcher Allen Medical Center and became Director of Nuclear Cardiology and Professor of

From the Nuclear Cardiology Laboratory, Henry Low Heart Center, Division of Cardiology, Hartford Hospital, ${ }^{\text {a }}$ Hartford, CT; and University of Connecticut School of Medicine, ${ }^{\mathrm{b}}$ Farmington, CT.

Reprint requests: Gary V. Heller, MD, PhD, University of Connecticut School of Medicine, Farmington, CT; gheller@harthosp.org.

J Nucl Cardiol 2010;17:979-80.

$1071-3581 / \$ 34.00$

Copyright (C) 2010 American Society of Nuclear Cardiology.

doi:10.1007/s12350-010-9309-0

Medicine at the University of Vermont School of Medicine. He remained in Vermont his entire academic career.

His strong interest in Nuclear Cardiology research resulted in a publication in 1983, one of the first describing the relationship between the severity of stress-induced perfusion abnormalities and outcomes in patients undergoing planar thallium-201 imaging. These and other early papers confirming the important relationship of nuclear imaging to risk stratification heralded a new approach to imaging beyond diagnosis alone. It is safe to say that his contributions impacted on the lives of thousands of patients as nuclear imaging testing procedures shifted focus from diagnosis to risk stratification. This approach continues today.

Dr. Brown's specific research focus was that of evaluating patients' post-myocardial infarction. At that time he began investigating pharmacologic stress imaging, low-level exercise testing was the preferred study of choice but performed as long as 10-14 days following admission. Dr. Brown and his colleague, Dr. Chambers, reported a small study examining the value of vasodilator stress imaging early after myocardial infarction (3-5 days). Their pioneer study demonstrated potential for determining at-risk patients and reducing hospital stay. This small study led to a multicenter evaluation spearheaded by Dr. Brown, myself, and Dr. Leslie Shaw examining 451 patients following acute myocardial infarction. The results of this study clearly demonstrated that early vasodilator stress myocardial perfusion imaging could successfully risk-stratify patients post myocardial infarction leading to earlier discharge of appropriate patients. This study was published in Circulation in 1999 and heralded further postMI evaluations such as the INSPIRE Study by Mahmarian and colleagues. All these trials demonstrated the value of vasodilator stress myocardial perfusion imaging in patients following infarction who have not undergone revascularization procedures.

Dr. Brown was a tireless advocate for the field of Nuclear Cardiology, as demonstrated by his research. He was also a pioneer in the development of the American Society of Nuclear Cardiology (ASNC). As the field of Cardiovascular Nuclear Cardiology grew and became increasingly relevant to cardiology and decision-making, 
Dr. Brown and colleagues recognized the need for a separate organization. From multiple meetings, a new organization emerged spearheaded by Drs. Brown, Wackers, Iskandrian, Verani, Leppo, Cerqueira, and others. He wrote the first By-Laws and participated in the first Executive Committee as Treasurer.

Dr. Brown and Dr. Cerqueira developed the first "Tutorial in Nuclear Cardiology", held in 1996 in Washington, DC. This was attended by some 300 physicians, technologists, and allied personnel. This meeting became the basis for the annual ASNC Scientific Sessions, just completed in Philadelphia, Pennsylvania with over 1,700 participants. He was also instrumental in the development of the Certification Examination in Nuclear Cardiology, now CBNC, which has certified over 7,000 physicians. Dr. Brown was remembered by both Drs. Wackers and Leppo as quiet, but determined and always could be called upon to complete the task. For this reason he was asked and willingly participated in many aspects critical to the development of ASNC.

Dr. Brown became the 6th ASNC President in 1998-1999. His goal was continuing development of ASNC and Nuclear Cardiology within Cardiology, and helped forge relationships with other organizations such as the American College of Cardiology (ACC). His editorials spoke to his passion for Nuclear Cardiology, having the foresight to promote molecular imaging and the use of newer technologies to advance cardiovascular nuclear imaging. Most recently, Dr. Brown served as a section editor for the Journal of Nuclear Cardiology for which he provided periodic updates on important articles published in other journals pertaining to the field of nuclear cardiology.

Dr. Brown approached all aspects of his life with extreme vigor. He was an avid mountain climber and ice climber. He scaled many of the important mountains in North America including those in the Rockies, Cascades, Ecuador, and Bolivia. He scaled challenging ice faces including Raves 5th in Labrador, Canada. Ken too was an avid bicyclist, not easy in Vermont. He completed the Ride Vermont in a Day Meet over 200 mountain miles. He was a loving, caring husband, and father. His last days were spent in Key West, Florida where he rode a scooter to many beaches, restaurants, galleries, and musical events. Donations in Kenneth Brown's name can be made to the Chittenday County Branch of the Sierra Club (vermont@sierraclub.org).

He will be missed. 